\title{
O DIREITO FINANCEIRO PODE SER A SOLUÇÃO PARA OS SEM-TETO
}

Coluna publicada em 29.7.2014: <http://www.conjur.com.br/2014-jul-29/ poder-publico-financiamento-direito-moradia $>$

Há várias semanas, movimentos dos "sem-teto" realizam manifestações nas quais reivindicam aquele que é hoje um direito humano universal e constitucionalmente assegurado no Brasil como um direito social: o direito à moradia (CF, art. $6^{\circ}$, caput).

Introduzido em nosso texto constitucional pela Emenda 26, de 14 de fevereiro de 2000 - o que permite dizer estar recentemente contemplado em nossa Constituição -, o direito à moradia já está há muito consagrado na Declaração Universal dos Direitos Humanos, proclamada pela Assembleia Geral das Nações Unidas em $1948^{1}$ e em muitos outros tratados internacionais e constituições pelo mundo afora.

Nada mais coerente com nosso ordenamento jurídico, cuja Constituição, em seu preâmbulo, prevê sermos um Estado Democrático "destinado a assegurar o exercício dos direitos sociais e individuais, a liberdade, a segurança, o bem-estar, o desenvolvimento, a igualdade e a justiça como valores supremos", e tem como um de seus fundamentos a dignidade da pessoa humana (art. 1º, III), que não há como se reconhecer presente àqueles que vivem em habitações precárias e sem as mínimas condições de segurança e higiene.

Trata-se de um direito fundamental de segunda dimensão que exige prestações positivas do Estado para que se torne real e seja efetivamente exercido. Um direito que tem custos - e não são pequenos, pelo contrário.

1 Artigo XXV, 1: "Toda pessoa tem direito a um padrão de vida capaz de assegurar a si e a sua família saúde e bem-estar, inclusive alimentação, vestuário, habitação, cuidados médicos e os serviços sociais indispensáveis, e direito à segurança em caso de desemprego, doença, invalidez, viuvez, velhice ou outros casos de perda dos meios de subsistência fora de seu controle”. 
$\mathrm{E}$, apesar de todo o debate acerca do tema, provocado pelas recentes manifestaçōes, essa questão, e outras que estão diretamente ligadas ao Direito Financeiro, ficaram marginalizadas. Pouco se falou sobre elas.

É certo que as manifestações atuais tiveram como principal motivo a discussão e aprovação do Plano Diretor na cidade de São Paulo, o que deu às questôes de direito urbanístico maior relevância. Mas não precisavam, nem deveriam, deixar o Direito Financeiro de lado. Afinal, sem desmerecer os aspectos urbanísticos desse debate, dificilmente o direito à moradia será exercido em sua plenitude sem que se façam ajustes e se construam mecanismos financeiros adequados para solucionar este problema.

Muitas questões - e não seria exagerado dizer, as principais - estão no âmbito das finanças públicas e carecem de maiores discussões em busca de soluções.

Veja-se inicialmente a questão federativa.

Nossa Constituição estabelece, no artigo 23, IX, que é competência comum da União, dos estados, do Distrito Federal e dos municípios "promover programas de construção de moradias e a melhoria das condições habitacionais e de saneamento básico".

Todos os entes da federação têm, portanto, responsabilidade em garantir condições dignas de habitabilidade aos cidadãos. Mas não há clareza sobre quais sejam as atribuições de cada um, o que evidentemente prejudica sobremaneira as ações governamentais nesse setor.

Trata-se de mais um caso em que se vê presente o federalismo cooperativo que caracteriza nosso Estado, que exige estudos e debates para estabelecer regras claras que permitam a colaboração de forma coordenada entre os entes federados de modo a maximizar os resultados em ações conjuntas. E que devem ser realizadas de forma planejada e benéfica a todos os envolvidos, aperfeiçoando a legislação existente. ${ }^{2}$

Nota-se também que as ações governamentais no setor habitacional ainda não se mostram coesas, constatando-se haver em todos os entes da federação medidas de várias espécies voltadas a atender as necessidades públicas nesse setor.

É o caso, por exemplo, do "aluguel social" ou "bolsa-aluguel”, benefício concedido em caráter temporário por alguns entes da federação para famílias de baixa renda, ou em áreas de risco, com base na Lei Orgânica da Assistência Social, que tem como objetivos garantir direitos sociais mínimos, ${ }^{3}$ para o que prevê benefícios

2 Com destaque para o Sistema Nacional de Habitação de Interesse Social, previsto na Lei 11.124 , de 16 de junho de 2005.

3 LOAS - Lei 8.742, de 1993, art. 2º parágrafo único. 
eventuais destinados a atender necessidades advindas de situações de vulnerabilidade temporária, ${ }^{4}$ entre os quais estão a falta de domicílio, como se vê, inúmeras vezes, em desastres e situações de calamidade pública. ${ }^{5}$ Regra geral, são benefícios que ocorrem de forma esparsa e casuística, como se vê em casos de enchentes, desabamentos, incêndios ou em remoções de favelas por razôes diversas.

Ou ainda de programas especiais de construção de moradias, como, por exemplo, o Programa Morar Seguro, instituído pelo estado do Rio de Janeiro, que prevê a "construção de unidades habitacionais para o reassentamento da população que vive em áreas de risco", instituído em função da "tragédia ocorrida na Região Metropolitana do estado do Rio de Janeiro", a ser realizado em parceria com as Prefeituras. ${ }^{6}$

No âmbito federal, destaca-se o Programa Minha Casa Minha Vida (PMCMV), previsto na Lei 11.977, de 2009, que tem por finalidade criar mecanismos de incentivo à produção e aquisição de novas unidades habitacionais, requalificação de imóveis urbanos e produção ou reforma de habitações rurais, para o que prevê uma série de medidas de natureza financeira, entre as quais a concessão de subvençōes e participação em fundos públicos financeiros, em ações, no mais das vezes, em regime de cooperação com outros entes da federação.

O Poder Executivo Federal, no orçamento de 2014, administra o programa orçamentário "Moradia Digna", 7 sob comando do Ministério das Cidades, que tem como objetivo "ampliar por meio de produção, aquisição ou melhoria o acesso à habitação, de forma subsidiada ou facilitada, priorizando o atendimento à população de baixa renda, com auxílio de mecanismos de provisão habitacional articulados entre diversos agentes e fontes de recursos, fortalecendo a implementação do Programa Minha Casa, Minha Vida”, e nele se constata serem de várias naturezas as iniciativas adotadas: concessão de subvenções, colaboração na provisão ou reforma de unidades habitacionais, melhoria na infraestrutura, apoio a projetos habitacionais, além de outras.

E vários são os órgãos envolvidos, como o Ministério das Cidades e a Caixa Econômica Federal, na esfera federal, empresas estaduais e municipais, como $\mathrm{CDHU}^{8}$ e Cohab, ${ }^{9}$ o que torna ainda mais necessário organizar políticas públicas que permitam a todos atuar de forma coordenada, com unidade de propósitos.

\footnotetext{
Lei 8.472, de 1993, art. 22.

Decreto Federal 6.307, de 2007, artigos $7^{\circ}$ e $8^{\circ}$.

6 Decreto Estadual 42.406, de 13 de abril de 2010.

7 Programa 2.049, orçamento federal de 2014 - Lei 12.952, de 20 de janeiro de 2014.

8 Companhia de Desenvolvimento Habitacional Urbano do Estado de São Paulo.

9 Companhia de Habitação de São Paulo (Município).
} 
Vários fundos financeiros têm direta ligação com o financiamento do direito à moradia, como o Fundo Nacional de Habitação de Interesse Social (FNHIS), Fundo de Amparo ao Trabalhador (FAT), Fundo de Garantia por Tempo de Serviço (FGTS), Fundo Garantidor de Habitação Popular (FGHab), apenas para citar alguns.

Vê-se existir uma multiplicidade de instrumentos de caráter essencialmente financeiro que todos os entes da federação usam e podem usar para, se não resolver, ao menos colaborar para melhorar as condições de moradia que ainda são por demais deficientes em nosso país.

Iniciativas como o Plano Nacional de Habitação (PlanHab), ${ }^{10}$ do Ministério das Cidades, com previsão de soluçôes de longo prazo (2009-2023) para os problemas habitacionais, devem ser objeto de atenção e apoio, com ajustes se necessário, especialmente no que tange a seus aspectos financeiros, a fim de dar maior coesão e lógica às medidas nesse setor.

Porém, o mais curioso é saber que tramita há anos no Congresso Nacional a Proposta de Emenda Constitucional 285, de 2008 - a "PEC da Habitação", e pouco ou nada se ouviu falar sobre ela durante os movimentos sociais recentes. Uma pena. Oportunidade que não se deveria perder para promover medida concreta no sentido de se efetivar esse direito tão fundamental para as famílias que têm na moradia a base para uma vida digna.

A PEC da Habitação prevê a inclusão de artigo no Ato das Disposiçõos Constitucionais Transitórias e se fundamenta em instrumentos financeiros para viabilizar a eliminação do déficit habitacional, com a destinação mínima de recursos orçamentários aos fundos de habitação de interesse social por todos os entes da federação.

Não se pode adiantar que seja a medida mais adequada e capaz de resolver os problemas, pois, como já foi escrito anteriormente neste mesmo espaço, as "vinculações" são instrumentos que, "por si só, pouco representam em termos de melhoria da qualidade do gasto público" e aumento na eficácia de políticas públicas. ${ }^{11}$

Mas há que se "tirar da gaveta" a referida PEC e retomar o debate.

Já passou a hora de se dar mais atenção a este assunto, até porque sua solução ainda está sendo tomada no âmbito dos Poderes Executivo e Legislativo, sendo incipiente a judicialização dessas questões, que, se não resolvidas brevemente, só tenderão a piorar, como se vê pelos sinais que a população nas ruas está emitindo.

10 BRASIL. Ministério das Cidades. Plano Nacional de Habitação. Versão para debates. Brasília: Ministério das Cidades/Secretaria Nacional de Habitação, maio de 2000.

11 Ver Vinculaçôes orçamentárias não são a panaceia dos problemas, nesta edição, p. 207-210. 